Int. J. Electrochem. Sci., 13 (2018) $9551-9560$

International Journal of

ELECTROCHEMICAL

SCIENCE

www.electrochemsci.org

\title{
Comparison of Potentiometric and ETAAS Determination of Copper and Iron in Herbal Samples
}

\author{
Ante Prkic ${ }^{1, *}$, Ivana Mitar ${ }^{2}$, Josipa Giljanovic ${ }^{1}$, Vesna Sokol ${ }^{3}$, Perica Bošković ${ }^{2}$, Ivan Dolanc ${ }^{4}$, \\ Tina Vukušićc ${ }^{1}$ \\ ${ }^{1}$ Department of Analytical Chemistry, Faculty of Chemistry and Technology, University of Split, \\ Ruđera Boškovića 35, 21000 Split, Croatia. \\ ${ }^{2}$ Department of Chemistry, Faculty of Science, University of Split, Ruđera Boškovića 33, 21000 Split, \\ Croatia. \\ ${ }^{3}$ Department of Physical Chemistry, Faculty of Chemistry and Technology, University of Split, \\ Ruđera Boškovića 35, 21000 Split, Croatia. \\ ${ }^{4}$ Institute for Anthropological Research, Ljudevita Gaja 32, 10000 Zagreb, Croatia. \\ *E-mail: prkic@ktf-split.hr
}

doi: $10.20964 / 2018.10 .18$

Received: 6 June 2018 / Accepted: 17 July 2018 / Published: 1 September 2018

The metal content (iron and copper) was potentiometrically analyzed in 44 tea samples. The analyzed samples included chamomile (Matricaria chamomilla), green tea (Camellia sinensis), sage tea (Salvia officinalis L.), linden (Tilia L.) and mint (Mentha piperita) in tea bags and bulk purchased at local supermarkets and marketplaces in Split, Croatia. Tea samples digestion was performed in microwave oven by using nitric acid and hydrogen peroxide mixture. Potentiometric determination was performed by using FISE for $\mathrm{Fe}^{3+}$ and CuISE for $\mathrm{Cu}^{2+}$, respectively, by using potentiometric methods previously developed in our laboratory. The measured results were compared with atomic absorption spectrometric measurements from our previous research and showed notable statistical superposition.

Keywords: iron, copper, tea, potentiometric determination, ion-selective electrode

\section{$\underline{\text { FULL TEXT }}$}

(C) 2018 The Authors. Published by ESG (www.electrochemsci.org). This article is an open access article distributed under the terms and conditions of the Creative Commons Attribution license (http://creativecommons.org/licenses/by/4.0/). 